\title{
VALOR NUTRITIVO DE SEIS HÍBRIDOS DE SORGO COM CAPIM-SUDÃO AVALIADOS EM TRÊS CORTES E EM DUAS ÉPOCAS DE SEMEADURA
}

\author{
ALEXANDRE GUALBERTO PENNA ${ }^{1}$, ANA LUIZA COSTA CRUZ BORGES ${ }^{2}$, LÚCIO \\ CARLOS GONÇALVES 2 , SILAS PRIMOLA GOMES ${ }^{4}$, JOSÉ AVELINO SANTOS \\ RODRIGUES $^{3}$, CLÁUDIA FREIRE ANDRADE MORAIS PENNA² ${ }^{2}$ IRAN BORGES ${ }^{2}$, \\ DÉCIO SOUZA GRAÇA ${ }^{2}$ RICARDO REIS E SILVA ${ }^{4}$
}

${ }^{1}$ Mestre em Zootecnia pela Escola de Veterinária da UFMG, Cx. Postal 567, CEP: 30123-970 Belo Horizonte, $M G$, Brasil

${ }^{2}$ Professor(a) da Escola de Veterinária da UFMG, Cx. Postal 567, CEP: 30123-970 Belo Horizonte, MG, Brasil, E-mail: analuiza@vet.ufmg.br

${ }^{3}$ Pesquisador da Embrapa Milho e Sorgo, Cx. Postal 151, CEP: 30123-970 Sete Lagoas, MG, Brasil,E-mail: avelino@cnpms.embrapa.br

${ }^{4}$ Doutorando em Zootecnia pela Escola de Veterinária da UFMG, Cx. Postal 567, CEP: 30123970 Belo Horizonte, MG, Brasil,E-mail: ricreis1@hotmail.com

Revista Brasileira de Milho e Sorgo, v.9, n.2, p.147-161, 2010

RESUMO - Foram avaliados quatro híbridos experimentais e dois híbridos comerciais de Sorghum bicolor cv bicolor X Sorghum bicolor cv sudanense quanto ao valor nutritivo: proteína bruta (PB\%), digestibilidade in vitro da matéria seca (DIVMS\%), fibra em detergente neutro (FDN), fibra em detergente ácido (FDA), lignina, fósforo (P) e cálcio $(\mathrm{Ca})$. Os híbridos foram submetidos a três cortes sucessivos, realizados em duas épocas diferentes de semeadura. Foi empregado um delineamento experimental de blocos ao acaso e a comparação de médias foi efetuada pelo teste de SNK, a 5\% de probabilidade. Foram observadas diferenças entre os híbridos quanto aos valores de FDA, PB e P. Todos os híbridos apresentaram bons padrões de qualidade, demonstrando o grande potencial dos híbridos de sorgo com capim-sudão.

Palavras-chave: digestibilidade, forragem, pastejo, Sorghum bicolor. 


\title{
NUTRITIONAL VALUE OF SIX SORGHUM-SUDANGRASS HYBRIDS SUBMITTED TO THREE CUTS AND TWO PLANTING TIMES
}

\begin{abstract}
Four experimental hybrids and two commercial hybrids of Sorghum bicolor cv bicolor X Sorghum bicolor cv sudanense were evaluated regarding their nutritional value: crude protein (CP\%), dry matter in vitro digestibility (DMIVD \%), neutral detergent fiber (NDF), acid detergent fiber (ADF), lignin, $\mathrm{P}$ and Ca. The hybrids were submitted to three successive cuts, accomplished at two different planting times. A randomized blocks design was used and the comparison of means was done by using the SNK test $(\mathrm{p}<0.05)$. The hybrids showed differences regarding ADF, CP and P. All the evaluated hybrids showed good quality standard, showing the high potential of sorghum with sudangrass hybrids.
\end{abstract}

Key words: digestibility, forage, grazing, Sorghum bicolor.

A alimentação animal é um dos principais componentes do custo de produção da pecuária. No caso do gado leiteiro, mais de $50 \%$ dos custos diários com os animais podem ser decorrentes de sua alimentação. Ademais, nas condições do Brasil Central, no período de final do inverno e início da primavera, ocorre baixa disponibilidade e qualidade do volumoso, sendo essas as principais limitações para a máxima produção de animais em pastagens tropicais (Euclides, 2002). A utilização, nesse período, de uma gramínea anual cultivada supriria a necessidade de volumoso de boa qualidade.

De acordo com Zago (1997), o capim-sudão e seus híbridos com o sorgo vêm ganhando importância crescente na alimentação de rebanhos de corte e de leite, por sua facilidade de cultivo, rapidez no estabelecimento e crescimento e, principalmente, pela facilidade de manejo para corte e/ou pastejo, além de bom valor nutritivo e da alta produção de forragem. Segundo Rodrigues (2000), os híbridos de sorgo com capim-sudão poderão se tornar uma alternativa viável para oferta de forragem verde de alto valor nutritivo, reduzindo o período de utilização de outros recursos forrageiros, minimizando os problemas decorrentes da estacionalidade da produção de forragem, principalmente em regiões onde períodos de estiagem ocorrem com frequência (Rodrigues, 2000). 
Segundo Wall \& Ross (1975), o valor nutritivo dos híbridos de sorgo Sudão com sorgo bicolor tem apresentado pouca variação entre os diferentes materiais; entretanto, há um efeito drástico da época da colheita sobre a qualidade nutricional. Esses autores observaram que o teor de $\mathrm{PB}$ da forragem diminuiu de 16,8 para $12,8 \%$ à medida que a planta se desenvolveu, passando de $45-65 \mathrm{~cm}$ de altura para $90-120 \mathrm{~cm}$, e atingiu 9,7\% no estádio de emborrachamento. Por outro lado, verificaram aumento nos teores de fibra bruta, passando de 24,1 para $31,1 \%$, de acordo com o aumento da altura, apresentando $34,7 \%$ no estádio de emborrachamento.

O trabalho foi realizado com o objetivo de avaliar o valor nutritivo de seis híbridos de sorgo (Sorghum bicolor cv bicolor) com capim-sudão (Sorghum bicolor cv sudanense), utilizados para a produção de forragem, submetidos a um regime de três cortes, em duas épocas distintas de semeadura.

\section{Material e Métodos}

O experimento foi instalado no município de Sete Lagoas, MG, em área da Embrapa Milho e Sorgo, no ano de 2001, entre as seguintes coordenadas geográficas: $19^{\circ}$ de latitude sul e $44^{\circ}$ de longitude oeste de Greenwich, com altitude média de $732 \mathrm{~m}$ e precipitação pluviométrica média de 1.340 $\mathrm{mm}$, da qual $86,2 \%$ ocorrem no período de novembro a abril. O clima da região é do tipo AW (classificação de Köppen), clima de savana, com inverno seco e a temperatura média no mês mais frio é acima de $18^{\circ} \mathrm{C}$.

$\mathrm{O}$ delineamento experimental empregado foi o de blocos ao acaso, com parcelas subdivididas, com quatro repetições, utilizando seis híbridos, três cortes sucessivos e duas épocas de semeadura. Foram cultivados seis híbridos, dos quais dois eram cultivares comerciais, híbridos do sorgo com capim-sudão, AG 2501-C e BRS 800, usados como testemunhas, e quatro eram genótipos experimentais, CMSXS 205 x CMSXS 912, CMSXS 206 x CMSXS 912, CMSXS 222 x CMSXS 912 e ATF53 x CMSXS 912, desenvolvidos pela Embrapa Milho e Sorgo. Para facilitar a descrição, os híbridos CMSXS foram designados apenas pelos seus números. Os dados foram avaliados por meio de análise de variância e teste de média, utilizandose o Sistema de Análises Estatísticas e Genéticas (SAEG) (UFV, 2000). Para a comparação das médias, foi empregado o teste SNK (Student Newman Keuls) a 5\% de probabilidade.

As semeaduras foram realizadas utilizando-se quatro canteiros por híbrido, distribuídos aleatoriamente em quatro fileiras diferentes (um por fileira), totalizando 24 canteiros por época. Cada canteiro continha quatro linhas de $5 \mathrm{~m}$ de comprimento e espaçamentos de $0,35 \mathrm{~m}$. Foram realizadas adubações durante a semeadura, utilizandose $300 \mathrm{~kg} / \mathrm{ha}$ da formulação 04-14-08 (N: P: K) e cobertura com $100 \mathrm{~kg}$ de ureia/ha. Quando necessário, durante todo o ensaio, foram realizadas irrigações por aspersão. 
As temperaturas médias observadas no local nos últimos anos, para os meses de outubro, novembro, dezembro e janeiro, foram, respectivamente, de 22,$1 ; 22,1 ; 22,3$ e $22,9^{\circ} \mathrm{C}$, enquanto que a precipitação média dos últimos anos foi de 115,7; 217,2; 266,3 e $289 \mathrm{~mm}$, respectivamente.

A primeira semeadura foi realizada no dia 22 de agosto, mês em que, no local experimental, ocorre elevação da temperatura, permitindo bom desenvolvimento das plantas forrageiras, quando corrigidas as deficiências hídricas. Foram realizados três cortes sucessivos, sendo o primeiro no dia 11 de outubro, o segundo no dia seis de novembro e o terceiro em três de dezembro, aos 50 (cinquenta) dias após a semeadura, aos 26 (vinte e seis) e aos 27 (vinte e sete) dias de rebrota, respectivamente.

A segunda semeadura foi realizada no dia quatro de setembro, ou seja, 13 (treze) dias após a primeira. Também foram realizados três cortes consecutivos, sendo o primeiro no dia 22 de outubro, o segundo no dia 23 de novembro e o terceiro no dia três de janeiro, aos 48 (quarenta e oito) dias após a semeadura, aos 32 (trinta e dois) e aos 41 (quarenta e um) dias de rebrota, respectivamente.

Devido às condições ambientais desfavoráveis durante a realização do experimento, excesso de chuvas, não foi possível a padronização das idades dos cortes nas diferentes épocas, o que impediu a realização de colheitas no momento oportuno, bem como adubações e tratos culturais exatamente no momento planejado.

Posteriormente, foram realizados os cortes, colhendo-se todo o material presente no canteiro. A altura de corte utilizada foi de $20 \mathrm{~cm}$ acima do solo, visando-se uma simulação das condições de pastejo. Após o corte, o material colhido foi pesado em dinamômetro, para se obterem as produções de matéria verde (MV) e matéria seca (MS), em t.ha ${ }^{-1}$. As amostras obtidas foram encaminhadas ao Laboratório de Nutrição da Escola de Veterinária da UFMG.

O material foi pesado e secado em estufa de ventilação forçada a $65^{\circ} \mathrm{C}$, por 72 horas, e moído em moinho com peneira de $1 \mathrm{~mm}$, para posteriores análises. As amostras pré-secadas foram utilizadas para a determinação dos teores de $\mathrm{MS}$ a $105^{\circ} \mathrm{C}$ e de cinzas (Cunnif, 1995), digestibilidade in vitro da matéria seca (DIVMS), de acordo com o método de Tilley \& Terry (1963), fibra em detergente neutro, fibra em detergente ácido e lignina (FDN, FDA e lignina), segundo Van Soest et al. (1991), o teor de proteína bruta (PB), multiplicando-se por 6,25 o teor de nitrogênio obtido, pelo método de combustão de Dumas, em analisador Leco®FP-528.

As análises do teor de fósforo (P) foram executadas pelo método colorimétrico (Cunnif, 1995). As análises de cálcio (Ca) foram realizadas em espectrofotômetro de absorção atômica, no Laboratório do Instituto Mineiro de Agropecuária (IMA), segundo Silva \& Queiroz (2002). 


\section{Resultados e Discussão}

O teor médio de PB observado na primeira época de semeadura foi de 17,05 e superior $(p<0,05)$ ao verificado na segunda época $(15,57)$, apresentando grande semelhança com os valores encontrados por Edward Jr. et al. (1971).

$\mathrm{O}$ teor médio de $\mathrm{PB}$ do genótipo experimental 206 x 912 e do híbrido BRS 800 foi igual $(\mathrm{p}<0,05)$ e superior ao das demais cultivares (Tabela 1).

$\mathrm{Na}$ primeira época de semeadura e no primeiro corte realizado, o genótipo $206 \mathrm{x}$ 912 e as duas testemunhas experimentais, AG 2501-C e BRS 800, apresentaram valores de PB superiores aos dos demais híbridos. No segundo corte, a média obtida foi de 17,96\% e não foi observada diferença dentre os híbridos. No terceiro corte, o teor de PB do genótipo 206 × 912 foi maior do que o teor apresentado pelo genótipo ATF 53 x 912, enquanto que, para os demais híbridos, não se observou diferença significativa.

Todos os híbridos apresentaram variações significativas no conteúdo de $\mathrm{PB}$ em relação aos cortes. O híbrido ATF 53 x 912 apresentou diferenças significativas no decorrer dos cortes. Para o híbrido 206 x 912, o primeiro corte foi superior aos cortes sucessivos, enquanto que os demais apresentaram menores valores proteicos no terceiro corte, em relação aos cortes anteriores.

Na segunda época de semeadura apenas no terceiro corte verificaram-se diferenças $(p<0,05)$

TABELA 1. Teores de proteína bruta (\%) na matéria seca da planta de híbridos de sorgo, em diferentes épocas de semeadura e corte ${ }^{1}$.

\begin{tabular}{|c|c|c|c|c|c|c|c|}
\hline \multirow{3}{*}{ Híbridos } & \multicolumn{3}{|c|}{$1^{\mathrm{a}}$ Época } & \multicolumn{3}{|c|}{$2^{\text {a }}$ Época } & \multirow{3}{*}{ Média } \\
\hline & \multicolumn{3}{|c|}{ Cortes } & \multicolumn{3}{|c|}{ Cortes } & \\
\hline & $1^{\circ}$ & $2^{\mathbf{o}}$ & $3^{\circ}$ & $\mathbf{1}^{\circ}$ & $2^{\circ}$ & $3^{\circ}$ & \\
\hline $206 \times 912$ & $19,32 \mathrm{Aa}$ & $17,33 \mathrm{Ab}$ & $16,24 \mathrm{Ab}$ & $19,41 \mathrm{Aa}$ & $13,70 \mathrm{Ac}$ & $17,72 \mathrm{Ab}$ & $17,28 \mathrm{~A}$ \\
\hline $205 \times 912$ & $17,58 \mathrm{Ba}$ & $17,75 \mathrm{Aa}$ & $15,85 \mathrm{ABb}$ & $18,48 \mathrm{Aa}$ & $13,03 \mathrm{Ab}$ & $12,57 \mathrm{Cb}$ & $15,87 \mathrm{BC}$ \\
\hline ATF53x912 & $15,88 \mathrm{Bb}$ & $18,02 \mathrm{Aa}$ & $13,78 \mathrm{Bc}$ & $18,33 \mathrm{Aa}$ & $12,76 \mathrm{Ab}$ & $12,86 \mathrm{Cb}$ & $15,27 \mathrm{C}$ \\
\hline 222x912 & $16,66 \mathrm{Ba}$ & $17,35 \mathrm{Aa}$ & $14,67 \mathrm{ABb}$ & $19,01 \mathrm{Aa}$ & $13,16 \mathrm{Ab}$ & $14,48 \mathrm{BCb}$ & $15,89 \mathrm{BC}$ \\
\hline AG 2501-C & $19,50 \mathrm{Aa}$ & $18,94 \mathrm{Aa}$ & $14,30 \mathrm{ABb}$ & $18,09 \mathrm{Aa}$ & $13,04 \mathrm{Ab}$ & $13,43 \mathrm{Cb}$ & $16,21 \mathrm{~B}$ \\
\hline BRS 800 & $19,75 \mathrm{Aa}$ & $18,36 \mathrm{Aa}$ & $15,63 \mathrm{ABb}$ & $19,84 \mathrm{Aa}$ & $14,90 \mathrm{Ab}$ & $15,50 \mathrm{Bb}$ & $17,33 \mathrm{~A}$ \\
\hline Média & 18,12 & 17,96 & 15,07 & 18,86 & 13,43 & 14,43 & \\
\hline $\begin{array}{l}\text { Média das } \\
\text { épocas }\end{array}$ & & $17,05 \mathrm{a}$ & & & $15,57 \mathrm{~b}$ & & \\
\hline
\end{tabular}

${ }^{1}$ Médias seguidas de letras maiúsculas iguais na mesma coluna e minúsculas na mesma linha não diferem significativamente pelo teste $\mathrm{SNK}(\mathrm{p}<0,05) . \mathrm{CV}=6,79 \%$ 
entre os híbridos. O genótipo experimental 206 x 912 apresentou valor de PB superior aos demais. Observaram-se variações significativas no conteúdo proteico dos híbridos em relação aos cortes na segunda época, com todos apresentando maiores valores de PB no primeiro corte, em relação aos cortes posteriores.

Para os híbridos de sorgo com capimsudão, o estádio de desenvolvimento da planta é um fator capaz de modificar o conteúdo proteico, ocorrendo um decréscimo com a maturidade (Ademosum et al., 1968). Diversos fatores são capazes de alterar o conteúdo de proteína do sorgo x capim-sudão, tais como frequência de colheita, diferenças entre espaçamentos e adubações nitrogenadas. Mas o principal fator é, segundo Edward Jr. et al. (1971), a altura e a idade da planta no momento do corte, de forma que, à medida que a planta torna-se mais velha, ocorrem mudanças na sua constituição, como maior acúmulo de fibra e maior proporção de colmo na planta, o que acarreta redução no teor proteico.

$\mathrm{Na}$ primeira época de semeadura, os híbridos não apresentaram diferença na DIVMS na mesma época de corte, sendo verificado apenas efeito de corte para alguns híbridos. Nos genótipos 206 x 912, 205 x 912 e 222 x 912, não foi observado o efeito da sequência de cortes sobre a DIVMS.

TABELA 2. Valores de digestibilidade (\%) in vitro da matéria seca da planta de híbridos de sorgo, em diferentes épocas de semeadura e corte ${ }^{1}$.

\begin{tabular}{|c|c|c|c|c|c|c|c|}
\hline \multirow{3}{*}{ Híbridos } & \multicolumn{3}{|c|}{$1^{\text {a }}$ Época } & \multicolumn{3}{|c|}{$2^{a}$ Época } & \multirow{3}{*}{ Média } \\
\hline & \multicolumn{3}{|c|}{ Cortes } & \multicolumn{3}{|c|}{ Cortes } & \\
\hline & $\mathbf{1}^{\mathbf{0}}$ & $2^{\circ}$ & $3^{\circ}$ & $\mathbf{1}^{\circ}$ & $2^{\circ}$ & $3^{\circ}$ & \\
\hline $206 \times 912$ & $55,81 \mathrm{Aa}$ & $57,00 \mathrm{Aa}$ & $56,24 \mathrm{Aa}$ & $60,73 \mathrm{Aa}$ & $55,87 \mathrm{Ab}$ & $60,42 \mathrm{Aa}$ & $57,68 \mathrm{~A}$ \\
\hline $205 \times 912$ & $57,40 \mathrm{Aa}$ & $57,65 \mathrm{Aa}$ & $56,08 \mathrm{Aa}$ & $59,70 \mathrm{Aa}$ & $52,53 \mathrm{ABb}$ & $57,84 \mathrm{Aa}$ & $56,86 \mathrm{~A}$ \\
\hline ATF53 x 912 & $55,95 \mathrm{Aab}$ & $57,89 \mathrm{Aa}$ & $53,21 \mathrm{Ab}$ & $60,05 \mathrm{Aa}$ & $54,18 \mathrm{ABb}$ & 57,96 Aab & $56,54 \mathrm{~A}$ \\
\hline $222 \times 912$ & $57,29 \mathrm{Aa}$ & $58,30 \mathrm{Aa}$ & $56,60 \mathrm{Aa}$ & $58,86 \mathrm{Aa}$ & $49,59 \mathrm{Bb}$ & $57,27 \mathrm{Aa}$ & $56,32 \mathrm{~A}$ \\
\hline AG 2501-C & $56,90 \mathrm{Aa}$ & $58,28 \mathrm{Aa}$ & $52,91 \mathrm{Ab}$ & $60,49 \mathrm{Aa}$ & $55,96 \mathrm{Aa}$ & $60,22 \mathrm{Aa}$ & $57,46 \mathrm{~A}$ \\
\hline BRS 800 & $59,89 \mathrm{Aa}$ & $60,00 \mathrm{Aa}$ & $53,18 \mathrm{Ab}$ & $60,28 \mathrm{Aa}$ & $54,24 \mathrm{ABb}$ & $58,66 \mathrm{Aa}$ & $57,71 \mathrm{~A}$ \\
\hline Média & 57,21 & 58,19 & 54,70 & 60,02 & 53,73 & 58,73 & \\
\hline $\begin{array}{l}\text { Média das } \\
\text { épocas }\end{array}$ & & $56,70 \mathrm{a}$ & & & 57,49 a & & \\
\hline
\end{tabular}

${ }^{1}$ Médias seguidas de letras maiúsculas iguais na mesma coluna e minúsculas na mesma linha não diferem significativamente pelo teste SNK $(\mathrm{p}<0,05)$. $\mathrm{CV}=4,73 \%$

Revista Brasileira de Milho e Sorgo, v.9, n.2, p.147-161, 2010

Versão impressa ISSN 1676-689X / Versão on line ISSN 1980-6477 - http://www.abms.org.br 
Os demais híbridos apresentaram menores valores no terceiro corte.

$\mathrm{Na}$ segunda época, foi verificada diferença entre as cultivares apenas no segundo corte, o híbrido AG 2501-C e o genótipo 206 x 912 apresentam valores de digestibilidade superiores a do híbrido 222 x 912, enquanto que para os demais não foram observadas diferenças. A cultivar AG 2501-C apresentou estabilidade no teor de DIVMS com a sequência das colheitas; os demais híbridos apresentaram variações significativas em relação aos cortes, com menor valor para o segundo corte em relação aos outros, excetuando-se o genótipo ATF 53 x 912, que apresentou menor valor do segundo corte somente em relação ao primeiro.

Diversos trabalhos mostram que a digestibilidade da MS de híbridos de sorgo com capim-sudão decresce rapidamente com a maturidade da planta. Edwards Jr. et al. (1971) observaram que a digestibilidade da MS da forragem decresceu de $89 \%$, com uma semana de rebrota, quando as plantas tinham $34 \mathrm{~cm}$ de altura, para $57 \%$, com oito semanas, quando as plantas estavam com 270 a $275 \mathrm{~cm}$ de altura. Embora as condições experimentais sejam diferentes e impeçam maiores comparações, verifica-se que esses valores estão acima das médias obtidas neste experimento, que estão mais próximas das médias encontradas por Alkimim Filho (1998), de 52,97\%, com a variação de 49,02 a 56,79\%, para cinco híbridos. Segundo Edwards Jr. et al. (1971), a digestibilidade da MS de híbridos de sorgo com capim-sudão parece ser mais relacionada com a altura da planta e com a percentagem de folhas e hastes, do que com tempo de rebrota. Farias \& Winch (1987) observaram um decréscimo na DIVMS com o avanço da colheita, diminuindo de $74,4 \%$, com $0,5 \mathrm{~m}$, para $69,7 \%$, com $1,0 \mathrm{~m}$ de altura.

Os valores médios de DIVMS para a primeira e segunda épocas não diferiram entre si. Os resultados obtidos neste experimento, comparados com aqueles obtidos em outros experimentos, realizados sob condições diferentes de manejo, apresentaram valores inferiores. Isso pode ser devido principalmente ao maior teor de lignina observado nos híbridos desse experimento, conforme será visto mais à frente.

Segundo Van Soest (1994), o baixo valor de digestibilidade dos alimentos é capaz de inibir o consumo, devido à sua mais lenta taxa de passagem pelo trato digestivo. Contudo, os valores de digestibilidade do presente estudo são geralmente superiores aos encontrados para a maioria das forragens utilizadas no Brasil, de acordo com os valores apresentados pelas Tabelas Brasileiras de Composição de Alimentos para Bovinos (Valadares Filho et al., 2002). Devese ressaltar ainda que, segundo Reid (1964), pode-se esperar uma digestibilidade mais alta da forragem, pelo aumento da oportunidade de seleção por parte dos animais quando em pastejo.

O conteúdo de FDN é de importância para o estudo de híbridos de sorgo para corte e/ou pastejo, por relacionar-se, principalmente, com 
a limitação de consumo. O valor médio de FDN da segunda época foi superior ao valor médio da primeira época, provavelmente por que os cortes foram efetuados em plantas mais velhas. Não houve variações $(p>0,05)$ entre as médias dos híbridos, as quais se situaram entre 54,68 e $55,74 \%$ de FDN (Tabela 3). Comparando-se os híbridos, da mesma forma, não houve variações $(p>0,05)$ em nenhum dos cortes e em nenhuma das épocas avaliadas.

Quanto ao efeito do corte, apenas na primeira época houve diferença, com o híbrido BRS 800 e os genótipos 206 x 912 e 205 x 912 apresentando valores observados no segundo corte superiores aos do terceiro corte, sendo que, no híbrido BRS 800, este último foi semelhante ao do primeiro corte.

Os valores médios encontrados no atual experimento estão abaixo dos valores médios de FDN de 75,45\% observados por Alkimim Filho (1998), para seis híbridos de sorgo bicolor com capim-sudão, cortados em janeiro, aos 40 dias após a semeadura, e também abaixo dos valores médios de 69,53\% encontrados por Oliveira (1997), para cinco híbridos colhidos 60 dias após a semeadura, provavelmente porque, no nosso trabalho, os híbridos tiveram período de crescimento menor até o corte.

Da mesma forma, os valores de 69,69 e 70,54\%, encontrados por Ferreira et al. (2000), respectivamente para os híbridos BRS 800 e AG 2501-C, cortados aos 42 dias de

TABELA 3. Teores de fibra (\%) em detergente neutro na matéria seca da planta de híbridos de sorgo, em diferentes épocas de semeadura e corte ${ }^{1}$.

\begin{tabular}{|c|c|c|c|c|c|c|c|}
\hline \multirow{3}{*}{ Híbridos } & \multicolumn{3}{|c|}{$1^{a}$ Época } & \multicolumn{3}{|c|}{$2^{\text {a }}$ Época } & \multirow{3}{*}{ Média } \\
\hline & \multicolumn{3}{|c|}{ Cortes } & \multicolumn{3}{|c|}{ Cortes } & \\
\hline & $1^{\circ}$ & $2^{\circ}$ & $3^{\circ}$ & $1^{\circ}$ & $2^{\circ}$ & $3^{\circ}$ & \\
\hline $206 \times 912$ & $54,35 \mathrm{Aab}$ & $57,05 \mathrm{Aa}$ & $52,14 \mathrm{Ab}$ & $53,76 \mathrm{Aa}$ & $55,66 \mathrm{Aa}$ & $55,12 \mathrm{Aa}$ & $54,68 \mathrm{~A}$ \\
\hline $205 \times 912$ & $54,20 \mathrm{Aab}$ & $56,44 \mathrm{Aa}$ & $51,51 \mathrm{Ab}$ & $53,97 \mathrm{Aa}$ & $55,79 \mathrm{Aa}$ & $57,28 \mathrm{Aa}$ & $54,86 \mathrm{~A}$ \\
\hline ATF53 x 912 & $55,51 \mathrm{Aa}$ & $56,01 \mathrm{Aa}$ & $52,34 \mathrm{Aa}$ & $56,18 \mathrm{Aa}$ & $55,96 \mathrm{Aa}$ & $58,46 \mathrm{Aa}$ & $55,74 \mathrm{~A}$ \\
\hline $222 \times 912$ & $55,00 \mathrm{Aa}$ & $57,23 \mathrm{Aa}$ & $52,58 \mathrm{Aa}$ & $53,92 \mathrm{Aa}$ & $57,01 \mathrm{Aa}$ & $57,90 \mathrm{Aa}$ & $55,61 \mathrm{~A}$ \\
\hline AG 2501-C & $54,08 \mathrm{Aa}$ & $56,92 \mathrm{Aa}$ & $53,15 \mathrm{Aa}$ & $54,38 \mathrm{Aa}$ & $55,38 \mathrm{Aa}$ & $55,69 \mathrm{Aa}$ & $54,93 \mathrm{~A}$ \\
\hline BRS 800 & $52,94 \mathrm{Ab}$ & $58,33 \mathrm{Aa}$ & $50,48 \mathrm{Ab}$ & $53,71 \mathrm{Aa}$ & $57,36 \mathrm{Aa}$ & $56,07 \mathrm{Aa}$ & $54,81 \mathrm{~A}$ \\
\hline Média & 54,35 & 57,00 & 52,03 & 54,32 & 56,19 & 56,75 & \\
\hline $\begin{array}{l}\text { Média das } \\
\text { épocas }\end{array}$ & & $54,46 \mathrm{~b}$ & & & $55,76 \mathrm{a}$ & & \\
\hline
\end{tabular}

${ }^{1}$ Médias seguidas de letras maiúsculas iguais na mesma coluna e minúsculas na mesma linha não diferem significativamente pelo teste $\mathrm{SNK}(\mathrm{p}<0,05) . \mathrm{CV}=4,53 \%$ 
idade, também foram superiores aos obtidos pelas testemunhas neste experimento. Tomich (2003), trabalhando com 12 híbridos de sorgo bicolor com capim-sudão, manejados em três cortes sucessivos, encontrou valores médios de $63,5,56,9$ e 58,2\% para o primeiro, segundo e terceiro cortes, respectivamente, valores estes bem mais próximos ao do atual experimento. Os valores menores de FDN encontrados nesse experimento podem ser explicados não somente pelas condições ambientais diferentes que alteram o estádio de desenvolvimento das plantas, mas também pelo corte mais alto $(20 \mathrm{~cm}$ do solo) que foi realizado nos híbridos, alterando sua proporção de hastes e, dessa forma, sua composição fibrosa, bem como pela menor idade das plantas no momento do corte.

Os valores médios de FDA obtidos no presente estudo foram diferentes $(p<0,05)$ entre os híbridos e entre as épocas de semeadura, sendo o valor médio de FDA da segunda época de semeadura superior ao da primeira (Tabela 4).

O genótipo 222 x 912 apresentou média de FDA superior $(\mathrm{p}<0,05)$ ao valor obtido pelo genótipo 206 x 912. A diferença entre os híbridos na mesma época de corte foi verificada apenas na segunda época de semeadura, com valores semelhantes os híbridos no primeiro e terceiro cortes, enquanto que, no segundo corte, a cultivar BRS 800 apresentou valor superior ao genótipo ATF 53 x 912. Quanto ao efeito

TABELA 4. Teores de fibra (\%) em detergente ácido na matéria seca da planta de híbridos de sorgo, em diferentes épocas de semeadura e corte ${ }^{1}$.

\begin{tabular}{|c|c|c|c|c|c|c|c|}
\hline \multirow{3}{*}{ Híbridos } & \multicolumn{3}{|c|}{$1^{\text {a }}$ Época } & \multicolumn{3}{|c|}{$2^{\text {a }}$ Época } & \multirow{3}{*}{ Média } \\
\hline & \multicolumn{3}{|c|}{ Cortes } & \multicolumn{3}{|c|}{ Cortes } & \\
\hline & $1^{0}$ & $2^{\circ}$ & $3^{\circ}$ & $1^{0}$ & $2^{\circ}$ & $3^{\circ}$ & \\
\hline $206 \times 912$ & $28,67 \mathrm{Aa}$ & $29,47 \mathrm{Aa}$ & $29,60 \mathrm{Aa}$ & $29,05 \mathrm{Aa}$ & $32,65 \mathrm{ABa}$ & $29,81 \mathrm{Aa}$ & $29,88 \mathrm{~B}$ \\
\hline $205 \times 912$ & $29,33 \mathrm{Aa}$ & $27,33 \mathrm{Aa}$ & $29,89 \mathrm{Aa}$ & $30,01 \mathrm{Ab}$ & $35,69 \mathrm{ABa}$ & $33,59 \mathrm{Aa}$ & $30,97 \mathrm{AB}$ \\
\hline $\begin{array}{l}\text { ATF53 x } \\
912\end{array}$ & $30,85 \mathrm{Aa}$ & $29,59 \mathrm{Aa}$ & $31,19 \mathrm{Aa}$ & $31,54 \mathrm{Aa}$ & $32,10 \mathrm{Ba}$ & $33,58 \mathrm{Aa}$ & $31,47 \mathrm{AB}$ \\
\hline $222 \times 912$ & $30,49 \mathrm{Aa}$ & $29,34 \mathrm{Aa}$ & $31,04 \mathrm{Aa}$ & $31,67 \mathrm{Aa}$ & $34,99 \mathrm{ABa}$ & $33,07 \mathrm{Aa}$ & $31,77 \mathrm{~A}$ \\
\hline AG 2501-C & $30,23 \mathrm{Aab}$ & $28,62 \mathrm{Ab}$ & $32,52 \mathrm{Aa}$ & $30,81 \mathrm{Ab}$ & $34,84 \mathrm{ABa}$ & $30,56 \mathrm{Ab}$ & $31,26 \mathrm{AB}$ \\
\hline BRS 800 & $28,21 \mathrm{Aa}$ & $30,23 \mathrm{Aa}$ & $28,50 \mathrm{Aa}$ & $29,36 \mathrm{Ab}$ & $36,80 \mathrm{Aa}$ & $32,09 \mathrm{Ab}$ & $30,87 \mathrm{AB}$ \\
\hline Média & 29,63 & 29,10 & 30,46 & 30,41 & 34,51 & 32,12 & \\
\hline $\begin{array}{l}\text { Média das } \\
\text { épocas }\end{array}$ & & $29,73 \mathrm{~B}$ & & & $32,34 \mathrm{~A}$ & & \\
\hline
\end{tabular}

Revista Brasileira de Milho e Sorgo, v.9, n.2, p.147-161, 2010

Versão impressa ISSN 1676-689X / Versão on line ISSN 1980-6477 - http://www.abms.org.br 
do corte na primeira época de semeadura, os híbridos AG 2501-C e BRS 800 apresentaram valores superiores no segundo corte, em relação ao primeiro e ao terceiro cortes, e o genótipo 205 x 912 mostrou superioridade do segundo corte apenas em relação ao primeiro.

Comparando-se os cortes, na cultivar AG 2501-C, o teor de FDA do terceiro corte foi superior ao valor do segundo corte, enquanto que o valor apresentado no primeiro corte não foi diferente dos demais.

As médias de FDA encontradas neste experimento estão abaixo dos valores médios de 49,65 e 40,54\% encontrados por Alkimim Filho (1998) e Oliveira (1997), respectivamente, que colheram a forragem com maiores idades. Como foi explicado para os teores de FDN, a altura de corte pode justificar essas diferenças em relação à literatura.

Os teores médios de lignina não diferiram entre híbridos, período de corte e época de semeadura $(\mathrm{p}>0,05)$.

$\mathrm{Na}$ primeira época, não foram observadas diferenças no teor de lignina entre os híbridos. Os híbridos 206 x 912 e BRS 800 apresentaram respostas semelhantes entre os cortes, enquanto que, para os demais híbridos, os valores observados para o terceiro corte foram superiores ao primeiro e segundo cortes.

$\mathrm{Na}$ segunda época de semeadura, os híbridos apresentaram resposta semelhante à primeira época. O híbrido BRS 800 apresentou valores no primeiro e terceiro cortes inferiores ao segundo corte, enquanto os demais híbridos

TABELA 5. Teores de lignina (\%) na matéria seca da planta de híbridos de sorgo, em diferentes épocas de semeadura e corte ${ }^{1}$.

\begin{tabular}{|c|c|c|c|c|c|c|c|}
\hline \multirow{3}{*}{ Híbridos } & \multicolumn{3}{|c|}{$1^{\text {a Época }}$} & \multicolumn{3}{|c|}{$2^{\text {a }}$ Época } & \multirow{3}{*}{ Média } \\
\hline & \multicolumn{3}{|c|}{ Cortes } & \multicolumn{3}{|c|}{ Cortes } & \\
\hline & $1^{\circ}$ & $2^{\mathbf{o}}$ & $3^{\circ}$ & $1^{\circ}$ & $2^{\mathbf{o}}$ & $3^{\circ}$ & \\
\hline $206 \times 912$ & 4,73 Aa & $5,23 \mathrm{Aa}$ & $6,38 \mathrm{Aa}$ & $5,07 \mathrm{Aa}$ & $6,03 \mathrm{Aa}$ & $5,71 \mathrm{Aa}$ & $5,52 \mathrm{~A}$ \\
\hline $205 \times 912$ & $3,60 \mathrm{Ab}$ & $4,17 \mathrm{Aa}$ & $6,93 \mathrm{Aa}$ & $5,61 \mathrm{Aa}$ & 7,19 Aa & $5,27 \mathrm{Aa}$ & $5,46 \mathrm{~A}$ \\
\hline ATF53 x 912 & $4,41 \mathrm{Ab}$ & $5,24 \mathrm{Ab}$ & 7,04 Aa & 6,07 Aa & 6,07 Aa & $6,93 \mathrm{Aa}$ & $5,96 \mathrm{~A}$ \\
\hline $222 \times 912$ & $4,45 \mathrm{Ab}$ & $4,72 \mathrm{Ab}$ & 7,00 Aa & 6,51 Aa & 7,09 Aa & $6,42 \mathrm{Aa}$ & $6,03 \mathrm{~A}$ \\
\hline AG 2501-C & $4,19 \mathrm{Ab}$ & $5,29 \mathrm{Ab}$ & $7,82 \mathrm{Aa}$ & $5,89 \mathrm{Aa}$ & 7,73 Aa & $6,71 \mathrm{Aa}$ & $6,27 \mathrm{~A}$ \\
\hline BRS 800 & $4,20 \mathrm{Aa}$ & $5,93 \mathrm{Aa}$ & $5,66 \mathrm{Aa}$ & $5,63 \mathrm{Ab}$ & $8,31 \mathrm{Aa}$ & $5,46 \mathrm{Ab}$ & $5,86 \mathrm{~A}$ \\
\hline Média & 4,26 & 5,10 & 6,81 & 5,80 & 7,07 & 6,08 & \\
\hline $\begin{array}{l}\text { Média das } \\
\text { épocas }\end{array}$ & & $5,39 \mathrm{~b}$ & & & $6,32 \mathrm{a}$ & & \\
\hline
\end{tabular}

${ }^{1}$ Médias seguidas de letras maiúsculas iguais na mesma coluna e minúsculas na mesma linha não diferem significativamente pelo teste $\mathrm{SNK}(\mathrm{p}<0,05)$. CV $=19,65 \%$ 
apresentam teores de lignina estáveis com a sequência de colheita.

A média dos valores apresentados na segunda época foi superior ao valor médio observado na primeira época. Oliveira (1997) obteve valores médios de 4,29\%, enquanto Tomich (2003) encontrou valores médios de 3,37\% para 12 híbridos de sorgo com capimsudão, ambos os valores menores do que os apresentados por este trabalho. Segundo Van Soest (1994), altas temperaturas resultam em aumento da lignificação, o que poderia explicar em parte o maior teor de lignina observado no presente experimento, pois este foi realizado numa época quente do ano.

Os teores de fósforo observados para os híbridos nos diferentes cortes e épocas estão na Tabela 6. A cultivar BRS 800 apresentou maior teor de fósforo $(\mathrm{p}<0,05)$ em relação ao cultivar AG 2501-C e aos genótipos ATF 53 x 912 e 205 x 912. Os genótipos 206 x 912 e 222 x 912 também foram superiores $(\mathrm{p}<0,05)$ ao genótipo ATF 53 x 912, enquanto comparando-se os demais não houve variações $(p>0,05)$.

Verificando-se os valores da primeira época de semeadura, no primeiro corte, o genótipo 206 x 912 apresentou valor de fósforo superior ao do genótipo ATF 53 x 912 e semelhante aos demais. Não houve diferenças dentre os demais híbridos neste corte. Para a segunda e terceira colheitas, não foram notadas diferenças entre os híbridos nos teores de fósforo. À exceção do híbrido 206 x 912, que apresentou maior valor no primeiro corte em relação ao terceiro, os demais apresentaram estabilidade para este parâmetro no decorrer dos cortes.

TABELA 6. Teores de fósforo (\%) na matéria seca da planta de híbridos de sorgo, em diferentes épocas de semeadura e corte ${ }^{1}$.

\begin{tabular}{|c|c|c|c|c|c|c|c|}
\hline \multirow{3}{*}{ Híbridos } & \multicolumn{3}{|c|}{ 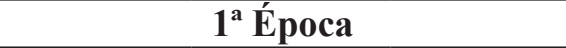 } & \multicolumn{3}{|c|}{$2^{\mathrm{a}}$ Época } & \multirow{3}{*}{ Média } \\
\hline & \multicolumn{3}{|c|}{ Cortes } & \multicolumn{3}{|c|}{ Cortes } & \\
\hline & $1^{\circ}$ & $2^{\circ}$ & $3^{\circ}$ & $1^{\circ}$ & $2^{\circ}$ & $3^{\circ}$ & \\
\hline $206 \times 912$ & 0,303 Aa & $0,268 \mathrm{Aab}$ & $0,242 \mathrm{Ab}$ & $0,275 \mathrm{Aab}$ & $0,255 \mathrm{Ab}$ & 0,313 Aa & $0,276 \mathrm{AB}$ \\
\hline $205 \times 912$ & $0,248 \mathrm{ABa}$ & $0,273 \mathrm{Aa}$ & $0,250 \mathrm{Aa}$ & $0,280 \mathrm{Aa}$ & $0,220 \mathrm{Ab}$ & $0,258 \mathrm{ABab}$ & $0,255 \mathrm{BC}$ \\
\hline ATF53 x 912 & $0,233 \mathrm{Ba}$ & $0,255 \mathrm{Aa}$ & $0,230 \mathrm{Aa}$ & $0,278 \mathrm{Aa}$ & $0,245 \mathrm{Aa}$ & $0,240 \mathrm{Ba}$ & $0,241 \mathrm{C}$ \\
\hline $222 \times 912$ & $0,258 \mathrm{ABa}$ & $0,250 \mathrm{Aa}$ & $0,288 \mathrm{Aa}$ & $0,295 \mathrm{Aa}$ & $0,235 \mathrm{Ab}$ & $0,280 \mathrm{ABa}$ & $0,268 \mathrm{AB}$ \\
\hline AG 2501-C & $0,243 \mathrm{ABa}$ & $0,265 \mathrm{Aa}$ & $0,258 \mathrm{Aa}$ & $0,293 \mathrm{Aa}$ & $0,233 \mathrm{Ab}$ & $0,263 \mathrm{ABab}$ & $0,259 \mathrm{BC}$ \\
\hline BRS 800 & $0,293 \mathrm{ABa}$ & $0,268 \mathrm{Aa}$ & $0,290 \mathrm{Aa}$ & $0,303 \mathrm{Aa}$ & $0,278 \mathrm{Aa}$ & $0,293 \mathrm{ABa}$ & $0,287 \mathrm{~A}$ \\
\hline Média & 0,222 & 0,263 & 0,258 & 0,316 & 0,244 & 0,275 & 0,264 \\
\hline $\begin{array}{l}\text { Média das } \\
\text { épocas }\end{array}$ & & $0,262 \mathrm{a}$ & & & $0,269 \mathrm{a}$ & & \\
\hline
\end{tabular}

Revista Brasileira de Milho e Sorgo, v.9, n.2, p.147-161, 2010

Versão impressa ISSN 1676-689X / Versão on line ISSN 1980-6477 - http://www.abms.org.br 
$\mathrm{Na}$ segunda época, não foram notadas diferenças entre os híbridos para as forragens colhidas no primeiro e segundo cortes, sendo encontradas médias gerais de 0,316 e $0,244 \%$, respectivamente. No terceiro corte, a percentagem apresentada pelo genótipo $206 \mathrm{x}$ 912 superou a encontrada para o genótipo ATF 53 x 912, sendo os demais híbridos semelhantes.

Comparando-se os cortes, apenas para os híbridos ATF 53 x 912 e BRS 800 foi observada uma estabilidade no teor de fósforo no decorrer do período, enquanto que para os demais híbridos o valor foi ora menor que o primeiro, ora menor que o terceiro, ou ainda menor que ambos. Os valores médios obtidos na primeira e segunda épocas de semeadura não diferiram entre si.

Apesar de as diferenças experimentais dificultarem as comparações, os teores de fósforo do presente trabalho estão próximos dos apresentados na literatura (Bishnoi et al., 1993, Pereira et al., 1993) e são superiores aos valores observados para a maioria das forragens utilizadas em pastejo no Brasil Central (Valadares Filho et al., 2002). Os teores médios de fósforo encontrados no presente trabalho são suficientes para suprir, segundo o Nutrient... (2001) as necessidades nutricionais de fósforo de novilhas e touros em crescimento e vacas gestantes secas, que estão ao redor de $0,26 \%$, desde que o consumo da forragem seja adequado. Dessa forma, os híbridos de sorgo com capim-sudão, também por este parâmetro, são uma boa opção para o uso como forragem.

Os teores de cálcio apresentados pelos híbridos estão na Tabela 7. Não houve diferenças

TABELA 7. Teores de cálcio (\%) na matéria seca da planta de híbridos de sorgo, em diferentes épocas de semeadura e corte.

\begin{tabular}{|c|c|c|c|c|c|c|c|}
\hline \multirow{3}{*}{ Híbridos } & \multicolumn{3}{|c|}{ 1 $^{\text {a Época }}$} & \multicolumn{3}{|c|}{$2^{\mathrm{a}}$ Época } & \multirow{3}{*}{ Média } \\
\hline & \multicolumn{3}{|c|}{ Cortes } & \multicolumn{3}{|c|}{ Cortes } & \\
\hline & $1^{\circ}$ & $2^{\circ}$ & $3^{\circ}$ & $1^{\mathrm{o}}$ & $2^{\circ}$ & $3^{\circ}$ & \\
\hline $206 \times 912$ & $0,47 \mathrm{Aa}$ & $0,44 \mathrm{Aa}$ & $0,41 \mathrm{Ba}$ & $0,40 \mathrm{Aa}$ & $0,37 \mathrm{Aa}$ & $0,47 \mathrm{Aa}$ & $0,43 \mathrm{~A}$ \\
\hline $205 \times 912$ & $0,54 \mathrm{Aa}$ & $0,45 \mathrm{Aa}$ & $0,50 \mathrm{ABa}$ & $0,47 \mathrm{Aa}$ & $0,32 \mathrm{Ab}$ & $0,50 \mathrm{Aa}$ & $0,46 \mathrm{~A}$ \\
\hline ATF53x912 & $0,51 \mathrm{Aa}$ & $0,40 \mathrm{Ab}$ & $0,48 \mathrm{ABab}$ & $0,44 \mathrm{Aa}$ & $0,41 \mathrm{Aa}$ & $0,46 \mathrm{Aa}$ & $0,45 \mathrm{~A}$ \\
\hline $222 \times 912$ & $0,45 \mathrm{Aa}$ & $0,46 \mathrm{Aa}$ & $0,51 \mathrm{ABa}$ & $0,43 \mathrm{Aab}$ & $0,35 \mathrm{Ab}$ & $0,45 \mathrm{Aa}$ & $0,44 \mathrm{~A}$ \\
\hline AG 2501-C & 0,49 Aab & $0,44 \mathrm{Ab}$ & $0,57 \mathrm{Aa}$ & $0,43 \mathrm{Aa}$ & $0,36 \mathrm{Aa}$ & $0,44 \mathrm{Aa}$ & $0,45 \mathrm{~A}$ \\
\hline BRS 800 & $0,49 \mathrm{Aa}$ & $0,47 \mathrm{Aa}$ & $0,43 \mathrm{Ba}$ & $0,47 \mathrm{Aab}$ & $0,40 \mathrm{Ab}$ & $0,51 \mathrm{Aa}$ & $0,46 \mathrm{~A}$ \\
\hline Médias & 0,49 & 0,44 & 0,48 & 0,44 & 0,37 & 0,47 & \\
\hline $\begin{array}{l}\text { Média das } \\
\text { épocas }\end{array}$ & & $0.47 \mathrm{c}$ & & & $0,43 \mathrm{~b}$ & & \\
\hline
\end{tabular}

Médias seguidas de letras maiúsculas iguais na mesma coluna, minúsculas na mesma linha não diferem pelo teste SNK $(\mathrm{p}<0,05) . \mathrm{CV}=13,34 \%$. 
( $p>0,05)$ entre os híbridos, que apresentaram valores entre 0,43 e $0,46 \%$ de cálcio na planta.

$\mathrm{Na}$ primeira época de semeadura, não foram observadas diferenças $(p>0,05)$ entre os híbridos no primeiro e segundo cortes. Para a cultivar AG 2501-C, o valor observado no terceiro corte foi superior ao da cultivar BR 800 e ao do genótipo 206 x 912, sendo que, para os demais híbridos, não foram observadas diferenças.

O genótipo ATF 53 x 912 apresentou menor $(\mathrm{p}<0,05)$ percentagem de cálcio no segundo corte em relação ao primeiro, enquanto que para o terceiro corte não foi observada diferença para os demais. Para a cultivar AG 2501-C, o teor de cálcio do terceiro corte foi superior ao do segundo corte, enquanto que o teor do primeiro corte não foi diferente dos outros dois. Para os demais híbridos, não foi observado o efeito da sequência de cortes na percentagem de cálcio.

$\mathrm{Na}$ segunda época de semeadura, não foram notadas diferenças nos teores de cálcio entre os híbridos. Para a cultivar AG 2501-C e os genótipos ATF 53 x 912 e 206 x 912, foi observada manutenção dos teores de cálcio com a sucessão de cortes, enquanto que para os demais foram notadas diferenças entre os cortes, com a tendência de menor teor para o segundo corte.

O valor médio de cálcio na primeira época foi superior $(\mathrm{p}<0,05)$ ao valor médio da segunda época. Pereira et al. (1993), trabalhando com o híbrido AG 2501-C, cortado entre os 76 e 84 dias de idade, encontrou teores médios de cálcio de
$0,52 \%$. O teor médio de cálcio encontrado tanto para a primeira quanto para a segunda época é suficiente, segundo o NRC (2001), para suprir as necessidades diárias de cálcio para novilhas e touros em crescimento e para vacas gestantes secas, que estão ao redor de $0,40 \%$, desde que a ingestão da forragem seja satisfatória.

Considerando os parâmetros produtivos dos diferentes híbridos avaliados, Penna et al. (2010) concluem que o híbrido ATF 53 x 912 apresentou níveis superiores de produção de MV, MS e matéria seca digestível nas duas épocas de semeadura em relação aos demais, o que demonstra seu elevado potencial para produção de forragem de boa qualidade.

\section{Conclusões}

Todos os híbridos apresentaram bons padrões de qualidade, demonstrando o grande potencial produtivo dos híbridos de sorgo com capim-sudão.

O genótipo ATF 53 x 912 destacouse dos demais genótipos experimentais, por apresentar maior potencial de crescimento e boa composição nutricional.

Os híbridos apresentaram maiores valores de $\mathrm{PB}$ e digestibilidade in vitro e menores teores de FDN, FDA e lignina no primeiro período de corte.

\section{Literatura Citada}

ADEMOSUM, A. A.; BAUMGARDT, B. R.; 
SCHOLL, J. M. Evaluation of a Sorghumsudangrass hybrid at varying stages of maturity on the basis of intake, digestibility and chemical composition. Journal of Animal Science, Champaign, v. 2, n. 3, p. 818-823, 1968.

ALKIMIM FILHO, J. F. Valor nutritivo de silagens de híbridos de Sorghum bicolor $\mathbf{x}$ Sorghum sudanense submetidos a diferentes tempos de pré-secagem. 1998. 95 f. Dissertação (Mestrado) - Escola de Veterinária, Universidade Federal de Minas Gerais, Belo Horizonte.

BISHNOI, U. R.; OKA, G. M.; FEARON, A. L. Quantity and quality of forage and silage of pearl millet in comparison to Sudax, grain, and forage sorghuns harvested at different growth stages. Tropical Agriculture, London, v. 70, n. 2, p. 98-102, 1993.

CUNNIF, P. (Ed.). Official methods of analysis of AOAC International. 16. ed. Washington: AOAC, 1995. 2000 p.

EDWARDS JR., N. C.; FRIBROURG, H. A.; MONTGOMERY, M. J. Cutting management effect on growth rate and dry matter digestibility of Sorghum-sudangrass cultivar Sudax SX-11. Agronomy Journal, Madison, v. 63, n. 2, p. 267-271, 1971.

EUCLIDES, V. P. B. Manejo de pastagens para bovinos de corte. In: CURSO DE PASTAGENS - etapa 2, 2002, Campo Grande. Programa Repastro - Seprod. Campo Grande: Repastro/ Embrapa Gado de Corte, 2002. p.1-21.
FARIAS, J. M.; WINCH, J. E. Effect of planting date and harvest stage upon yield, yield distribution and quality of Sorghum sudangrass in northern Mexico. Tropical Agriculture, London, v. 64, n. 2, p. 87-90, 1987.

FERREIRA， J. J.; CARNEIRO, J. C.; RODRIGUES, J. A. S.; BALIERO NETO, G. Produção e composição bromatológica do capim sudão e de seus híbridos (BRS 800 e AG 2501) com 42 e 56 dias. In: REUNIÃO DA SOCIEDADE BRASILEIRADEZOOTECNIA, 37., 2000, Viçosa, MG. Anais... Viçosa: SBZ, 2000. CD-ROOM.

NUTRIENT requirements of dairy cattle. 7. ed. Washington, D.C.: National Academic, 2001. $381 \mathrm{p}$.

OLIVEIRA, C. L. M. Avaliação nutricional de silagens de híbridos de Sorghum bicolor x Sorghum sudanense. 1997. 77 f. Dissertação (Mestrado) - Escola de Veterinária, Universidade Federal de Minas Gerais, Belo Horizonte.

PENNA, A. G.; BORGES, A. L. C. C.; GONÇALVES, L. C.; RODRIGUES, J. A. S.; GOMES, S. P.; PENNA, C. F. A. M.; BORGES, I.; RODRIGUES, N. M.; SILVA, R. R. Produção de seis híbridos de sorgo com capim-sudão avaliados em três cortes e em duas épocas de semeadura. Revista Brasileira de Milho e Sorgo, Sete Lagoas, v. 9, n. , p. 95-107, 2010.

PEREIRA, O. G.; OBEID, J. A.; GOMIDE, J. A.; QUEIROZ, A. C.; VALADARES FILHO, 
S. C. Produtividade e valor nutritivo de aveia (Avena sativa), milheto (Pennisetum americanum L.), e de um híbrido de Sorghum bicolor x S. sudanense. Revista Brasileira de Zootecnia, Vicosa, MG, v. 22, n. 1, p. 22-31, 1993.

REID, R. L.; CLARK, B.; JUNG, G. A. Studies with sudangrass. II. Nutritive evaluation by in vivo and in vitro methods. Agronomy Journal, Madison, v. 56, p. 537-541, 1964.

RODRIGUES, J. A. S. Utilização de forragem fresca de sorgo (Sorghum bicolor x Sorghum sudanense) sob condições de corte e pastejo. In: SIMPÓSIO DE FORRAGICULTURA E PASTAGENS, 1., 2000, Lavras. Temas em evidência. Lavras: UFLA, 2000. p. 179-201.

SILVA, D. J.; QUEIROZ, A. C. Análise de alimentos: métodos químicos e biológicos. Viçosa: UFV, 2002. 235 p.

TILLEY, J. M. A.; TERRY, R. A. A two-stage technique for the "in vitro" digestion of forage crops. Journal of the British Grassland Society, Oxford, v. 18, n. 2, p. 104-111, 1963.

TOMICH, T. R. Potencial forrageiro de híbridos de sorgo com capim Sudão (Sorghum bicolor $x$ Sorghum sudanense) avaliados em regime de corte. 2003. $88 \mathrm{f}$. Tese (Doutorado) - Escola de Veterinária, Universidade Federal de Minas Gerais, Belo Horizonte.

UNIVERSIDADE FEDERAL DE VIÇOSA. SAEG - Sistema de Análises Estatísticas e Genéticas (manual do usuário). Versão 8.0. Viçosa, MG, 2000.142 p.

VALADARES FILHO, S. C.; ROCHA JR., V. R.; CAPPELLE, E. R. Tabelas brasileiras de composição de alimentos para bovinos. Viçosa: UFV; DZO; DPI, 2002. 297 p.

VAN SOEST, P. J. Nutritional ecology of the ruminant. 2. ed. Ithaca: Cornell University Press, 1994. 476 p.

VAN SOEST, P. J.; ROBERTSON, J. B.; LEWIS, B.A. Methods for dietary fiber, neutral detergent, and nonstarch polysaccharides in relation to animal nutrition. Journal of Dairy Science, Champaign, v. 74, n. 10, p.35833597, 1991.

WALL, J. S.; ROSS, W. Produccion y usos del sorgo. Buenos Aires: Hemisferio Sur, 1975. $399 \mathrm{p}$.

ZAGO, C. P. Utilização do sorgo na alimentação de ruminantes. In: MANEJO cultural do sorgo para forragem. Sete Lagoas: EMBRAPACNPMS, 1997. p. 9-26. (EMBRAPA-CNPMS. Circular Técnica, 17). 
